\title{
Minimally invasive management of a foreignbody granuloma mimickingan infected urachal sinus
}

\begin{abstract}
Infected urachal sinusis a rare medical condition characterized by abdominal pain and purulent discharge trough umbilicus. It is usually diagnosed after a computed tomography. The best management is to resect all the remnant tissue. However surgical drainage can be performed before the definitive treatment. We report a case of a patient diagnosed with infected urachal sinus who underwent laparoscopic surgery with excellent results. Laparoscopy demonstrated to be safe and feasible to manage this type of urachalanomaly.
\end{abstract}

Keywords: urachus, laparoscopy, urachalsinus, urachalremnant
Volume 5 Issue 2 - 2017

\author{
Freitas DM,' Comin VM,' Spadoni VS, \\ Trohjan GP,' Leite LF' \\ 'Division of urology Nossa Senhora da Concei \\ ${ }^{2}$ Division of Ophthalmology, Hospital de Clinicas, Brazil
}

Correspondence: Daniel Melecchi de O Freitas, Division of
Urology, Nossa Senhora da Concei,Tel (5I) 998365520,

Email danielfreitas.usc@gmail.com

Received: April 26, 2017| Published: July 24, 2017

\section{Introduction}

Urachus is a fibrous and tubular structure linked with the bladder dome and the umbilicus that is obliterated after birth. Eventually, there are abnormalities with the closure of this structure during fetal life. When the urachus sells of distally and is opened at the umbilicus leading to and blind ending area it is called sinus. ${ }^{1}$ Although urachal remnants are mostly asymptomatic, urachal sinus may, sometimes, become infected. Abdominal pain and purulent drainage through the belly bottom are part of clinical presentation in these cases. Moreover, imaging exams, as ultrasound and computed tomography (CT), are helpful to confirm the diagnosis. ${ }^{2}$ The management of urachal sinus is surgical excision of all remnant tissue with dissection from the umbilicus to the bladder dome. Occasionally, a bladder cuff is resected when urinary fistula is present. ${ }^{3}$ Therefore we sought to report a case of a patient who was diagnosed with an infected urachal sinus and underwent laparoscopic treatment.

\section{Case presentation}

We report a case of a 72 years-old male patient who had history of previous purulent drainage through the belly bottom during the last 18 months. He had undergone to open appendectomy 14 years ago. During these episodes local treatment with topical antibiotics was performed with partial resolution. He came to the clinical office complaining about purulent discharge through the umbilicus again. $\mathrm{CT}$ showed a $4 \mathrm{~cm}$ fluid collection located in the infraumbilical middle line, communicating with the belly bottom Figure $(1 \& 2)$. The patient accepted to undergo surgery. We performed a laparoscopic approach. Before portal placement and pneumoperitoneum we dissected the infected area inside the umbilicus, sutured with 2-0 Vycril ${ }^{\circledR}$ and left the specimen inside the abdominal cavity. Figure 3 demonstrates our standard ports placement. After this, we placed a $10 \mathrm{~mm}$ port, 8 $\mathrm{cm}$ above the belly bottom and started the pneumoperitoneum. The camera was placed in this trocar. Another two $5 \mathrm{~mm}$ ports were placed lateral to the rectus abdominis, one for a grasper and the other for scissor (Figure 4) Adhesions were perceived during cavity inspection.. We dissected the urachus and. a retained suture material with intense inflammatory reaction was identified (Figure 5). Bladder resection was not needed. The surgical specimen was removed through a $5 \mathrm{~mm}$ portal. Fascia was sutured with 0 Vycril ${ }^{\circ}$. Estimated blood loss was not quantified. Operative time was 94 min.Patient was discharged
$24 \mathrm{~h}$ after the procedure and no early or late complications were reported after 60 days of follow-up. Pathology report demonstrated fibrotic connective tissue with chronic inflammation and foreign body granuloma in a $6.0 \times 2.0 \times 1.8 \mathrm{~cm}$ specimen.
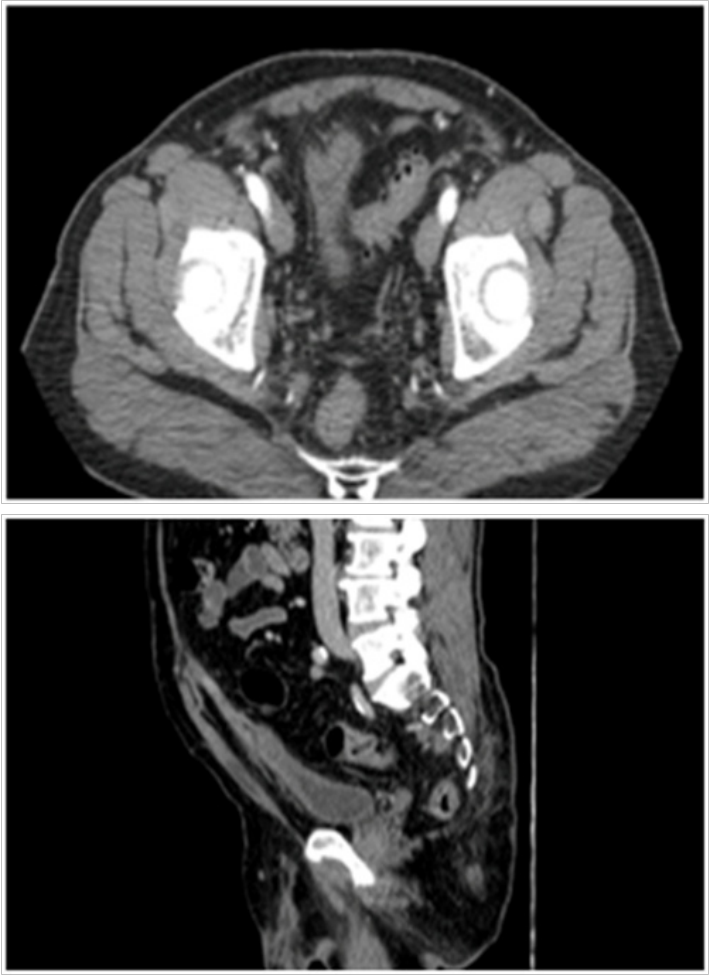

Figure I \& 2 CT sc an demonstrated images suggesting an infected urachusremnant.

\section{Discussion}

Congenital urachus remnants are uncommon diseases in adults and occur approximately in $1 / 8000$ patients with a male to female proportion of $3: 1 ., 5$ Acquired urachal anomalies may also be found. It is more frequently caused by bladder neck dysfunctions, lower urinary tract obstruction, neurogenic bladder or trauma. ${ }^{4}$ The first description of urachal disease in the literature was published by 
Cabrolius in $1550 .{ }^{6}$ In that case, the author described a young woman who presented with urinary discharged through the umbilicus and who was diagnosed with urachal fistula. ${ }^{6}$ In fact, congenital urachal anomalies can be divided in four main groups: patent urachus, urachal cyst, urachal sinus and vesicourachal diverticulum. ${ }^{7}$ The urachal cyst is the most prevalent in the adult age. ${ }^{7}$ However urachal disease can also be acquired and several possible causes have already been reported. For example, Murray et al. ${ }^{8}$ reported a case of urachal cyst caused by a blunt abdominal trauma. Clinical presentation depends on the type of the anomaly. Urinary discharge is present in vesicourachal fistula cases, painful palpable midline abdominal mass can be seen in infected cysts and the association with purulent discharge through the umbilicus can be caused by infected urachal sinus. ${ }^{9}$ Calcifications sometimes were present inside the remnant and are associated to infection. ${ }^{10}$

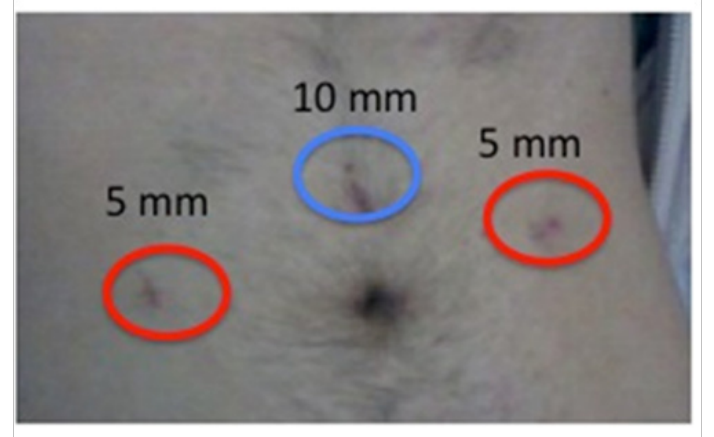

Figure 3 Portsplacement.

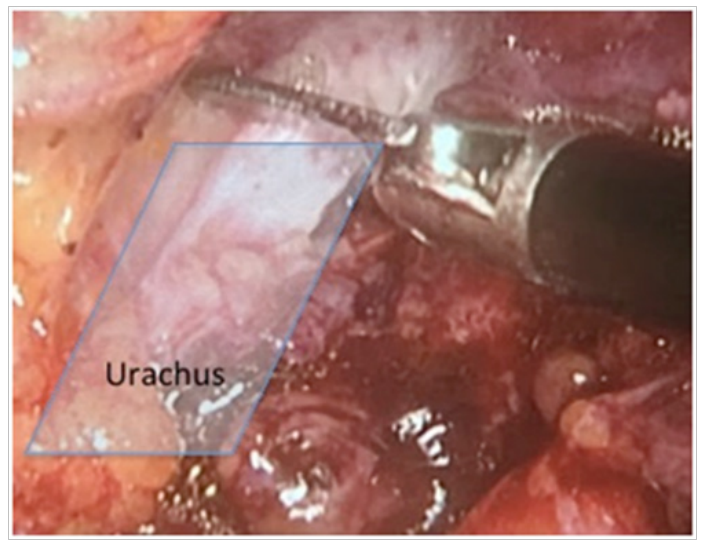

Figure 4 Dissection of suspected infected urachusremnat.

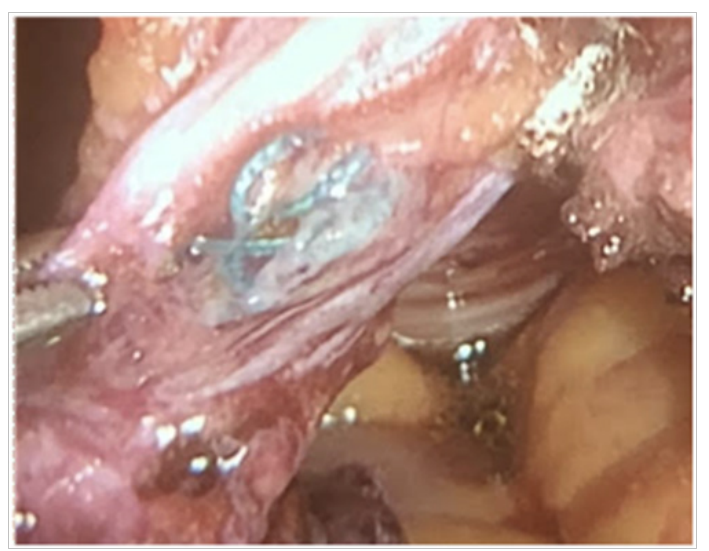

Figure 5 Retained suture material with intense inflammatory reaction.
Moreover, acute abdomen with peritonitis can occur with rupture of an infected sinus or cyst. ${ }^{11}$ Occasionally the diagnosis is incidental. For instance, Mac Lucas described a case of an urachal sinus that was diagnosed after a umbilical trocar placement during a laparoscopic surgery. ${ }^{11}$ During the cavity inspection the surgeon realized that he was actually inside urachal sinus. Adenocarcinoma of urachus is another possible differential diagnosis. ${ }^{12}$ Imaging studies are routinely used to confirm the diagnosis when urachus remnants are suspected. Although an abdominal ultrasound is commonly performed at the beginning of clinical investigation, CT scan is more accurate when infection is present. ${ }^{13}$ Furthermore, Mesrobian et al. ${ }^{14}$ who studied the usage of urethrocystography in the diagnosis of urachal anomalies. The authors found a extremely low accuracy for this method since $80 \%$ of the imaging studies were normal. ${ }^{15}$ Treatment of urachus anomalies is basically the excision of all remnant tissue with an eventual bladder dome resection. ${ }^{14,16}$ Some authors avoid excision of infected remnants and perform surgical drainage before the definitive treatment. ${ }^{14}$ Conversely, others recommend surgical treatment at the time of diagnosis with or without infection. ${ }^{16}$ Surgical approach can be conventional (open) or minimally invasive (laparoscopy or robotassisted). Usually, tree trocars are placed, one of 10 or $12 \mathrm{~mm}$ and two of $5 \mathrm{~mm}$ as described by Caddedu et al. ${ }^{17} \mathrm{We}$ used the same approach in our patient.

\section{Conclusion}

Urachal anomalies are not prevalent among adult population. However they should be thought, as a possible diagnose, when pain or discharged are noticed in umbilical region. Laparoscopic management of urachus sinus demonstrated to be safe, feasible and a good treatment option.

\section{Acknowledgments}

None.

\section{Conflicts of Interset}

None.

\section{References}

1. Scheye T, Vanneuville G, Amara BAnatomic basis of pathology of the urachus. SurgRadiol Anat. 1994;16(2):135-141.

2. Cilento BG, Bauer SB, Retik AB. Urachal anomalies: defining the best diagnostic modality. Urology. 1998;52(1):120-122.

3. Nargund VH, Donaldson RA. Urachal calculi: A case report and review of the literature. Int Urol Nephrol. 1994;26(4):409-411.

4. Walton B. Acute abdominal painsecondaryto a urachalcystabscess. $J$ Am Osteopath Assoc. 1998;98(1):51-52.

5. Lopez-Marti E, Prats-Lopez J, Prera-Vilaseca A. Vesico-umbilical fistula. Occurrence in anadult. Arch Esp Urol. 1993;46(4):337-339.

6. Begg RC. The urachusand umbilical fistulae. Surg Gynec Obstet. 1927;45: $165-167$.

7. Bauer SB, Retik A . Urachal anomalies and related umbilical disorders. Urol Clin North Am. 1978;5(1):195-211.

8. Murray DA, Michael T, Reeder DO. UrachalCyst in a Collegiate Football Player. Clin J Sport Med. 2004;14(2):101-102. 
9. Arintan B, Adkvni A. A Fatal Case of Ruptured Infected Urachal Cyst. $J$ UrolNephrol. 1985;17(2):133-138.

10. Nargund VH, Donaldson RA. UrachalCalculi: A case report and review of the literature. Int Urol Nephrol. 1994;26(4):409-411.

11. McLucas B, March C. Urachal sinus perforation during laparoscopy. A case report. J Reprod Med. 1990;35(5):573-574.

12. Kontogeorgos I, Kokotas N. Congenital Abnormalities of the Urachus. Int Urol Nephrol. 1977; 9(4):309-312.

13. Mesrobian HG, Zacharias A, Balcom AH, et al. Ten years of experience with isolated urachal anomalies in children. J Urol. 1977;158(3 Pt 2):1316-1318.
14. Minevich E, Wacksman J, Lewis AG. The infected urachalcyst: Primaryexcision versus a staged approach. JUrol. 1977;157(5):1869-1879.

15. Pesce C, Costa L, Musi L Campobasso P. Relevance of Infection in Children with Urachal Cysts. Eur Urol. 2000;38(4):457-460.

16. Tornero JL, Ponce de Leo 'J, Huguet J. Endoscopic approach of the overinfected urachal cyst. Int Urol Nephrol. 2002;34(3):289-291.

17. Cadeddu JA, Boyle KE, Fabrizio MD. Laparoscopic managementofurachalcyst in adulthood. J Urol. 2000;164(5): 1526-1528. 